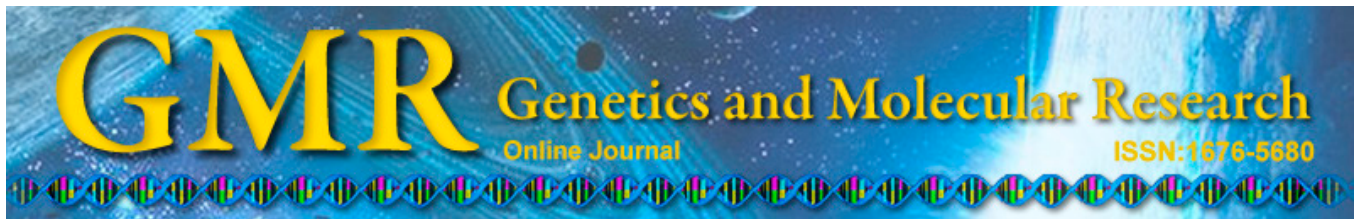

\title{
Screening of differentially-expressed genes in the muscles of rabbit breeds with expression profile chip
}

\author{
W.Z. Wang, T. Li, L.J. Shi, X.R. Yan, Y.L. Pan and X.S. Wu \\ College of Animal Science and Technology, Yangzhou University, Yangzhou, \\ Jiangsu Province, China
}

Corresponding author: X.S. Wu

E-mail: xswu@yzu.edu.cn

Genet. Mol. Res. 14 (3): 8038-8045 (2015)

Received November 4, 2014

Accepted March 26, 2015

Published July 17, 2015

DOI http://dx.doi.org/10.4238/2015.July.17.12

\begin{abstract}
The molecular mechanism underlying muscle development in rabbits is not well-understood. In the current study, differentially-expressed genes were scanned using an expression profile chip in New Zealand white rabbits (introduced breed) and Fujian yellow rabbits (local breed), and some of the genes were tested using reverse transcription-polymerase chain reaction. The amplification results were consistent with the microarray data. Fourteen and 13 genes involved in muscle development were identified in the dorsal longissimus and leg muscles, respectively. Myh6, Myh7, Myh7b, Myo5b, Tnnc1, Tpm3, and Acta2 were scanned in the longissimus and leg muscles. Thus, these genes may be involved in muscle fiber formation and muscle development in rabbits. This study provides a theoretical basis for improving meat quality, as well as for the future development and utilization of local meat rabbit breeds.
\end{abstract}

Key words: Differentially-expressed gene; Expression profile chip; Muscle; Rabbit; Reverse transcription-polymerase chain reaction 


\section{INTRODUCTION}

With improvements in the standard of living, rabbit meat is increasingly welcomed by consumers as a high-protein, low-fat, and low-cholesterol meat. Rabbit meat has a delicate texture and delicious taste and is rich in nutrients; thus, it is known as a "beauty meat" and "healthy meat", and is suitable for the elderly, women, the obese, and patients with liver disease, cardiovascular disease, and diabetes. The New Zealand white rabbit is one of the world's most well-known medium meat rabbit breeds because of its high growth rate, high feed conversion and slaughter rate, strong adaptability and disease resistance, and suitability for largescale farming. The Fujian yellow rabbit is a local variety in China and exhibits precocious puberty, succulent high nutritional value, resistance to crude feed, wide adaptability, and high dietary value. However, the early-stage growth rate of Fujian yellow rabbits is slower than that of the New Zealand white rabbits.

In the current study, the rabbit genome-wide expression profile chip was used to select differentially-expressed genes between introduced (New Zealand white rabbits) and local varieties (Fujian yellow rabbits) to establish a working base from which to elucidate the molecular mechanism underlying the functional genes determining rabbit muscle growth and development. We also provide a theoretical foundation for the exploitation and utilization of high-quality local meat rabbit varieties in China.

\section{MATERIAL AND METHODS}

\section{Sample collection}

The animal samples in the current study were collected from the Jinling Rabbit Farm (Nanjing, Jiangsu). New Zealand white rabbits and Fujian yellow rabbits were maintained under the same feeding and management conditions and slaughtered at 70 days of age ( 2 males and 2 females of each species). The dorsal longissimus and leg muscles were excised, rapidly immersed in liquid nitrogen, and stored at $-70^{\circ} \mathrm{C}$.

\section{RNA extraction and purification}

Total RNA was extracted using the TRIZOL method and evaluated for quality using an Agilent Bioanalyzer 2100 (Agilent Technologies, Santa Clara, CA, USA). RNA from the same parts from the same gender and species were mixed to yield 4 RNA samples (New Zealand white rabbit dorsal longissimus muscle and leg muscle, and Fujian yellow rabbit dorsal longissimus muscle and leg muscle). The RNA samples were then divided into 2 parts for microarray experiments and for fluorescence quantitative experiments to verify the reliability of the chip.

\section{Gene chip}

The Agilent rabbit genome-wide 4 x 44k chip (design ID: 020908) was purchased from Shanghai Biotechnology Corporation (Shanghai, China). 


\section{Microarray experiments}

\section{Chip hybridization}

Each slide was hybridized with $1.65 \mu \mathrm{g}$ Cy3-labeled cRNA using a Gene Expression Hybridization Kit in a Hybridization Oven (Agilent Technologies), according to manufacturer instructions. After 17-h hybridization, slides were washed in staining dishes (Thermo, Waltham, MA, USA) using a Gene Expression Wash Buffer Kit (Agilent Technologies) as recommended by the manufacturer.

\section{Data acquisition}

Slides were scanned using an Agilent Microarray Scanner (Agilent Technologies) with the following default settings: dye channel; green; scan resolution, $=5 \mu \mathrm{m}$; and PMT $100 \%, 10 \%$, and 16 bit. The scanned slides were then processed using the Feature Extraction software (10.7; Agilent Technologies). Raw data were normalized using the Quantile algorithm and Gene Spring Software ver. 11.0 (Agilent Technologies).

\section{Primer design and synthesis}

According to the rabbit gene mRNA sequence in GenBank, fluorescence quantitative primers for 7 genes were designed using Primer-BLAST online at NCBI, and reference gene glyceraldehyde 3-phosphate dehydrogenase primer sequences as described by $\mathrm{Wu}$ (2011). Primers were synthesized by Shanghai Sangon Biological Engineering Corporation (Shanghai, China). Primer sequences are shown in Table 1.

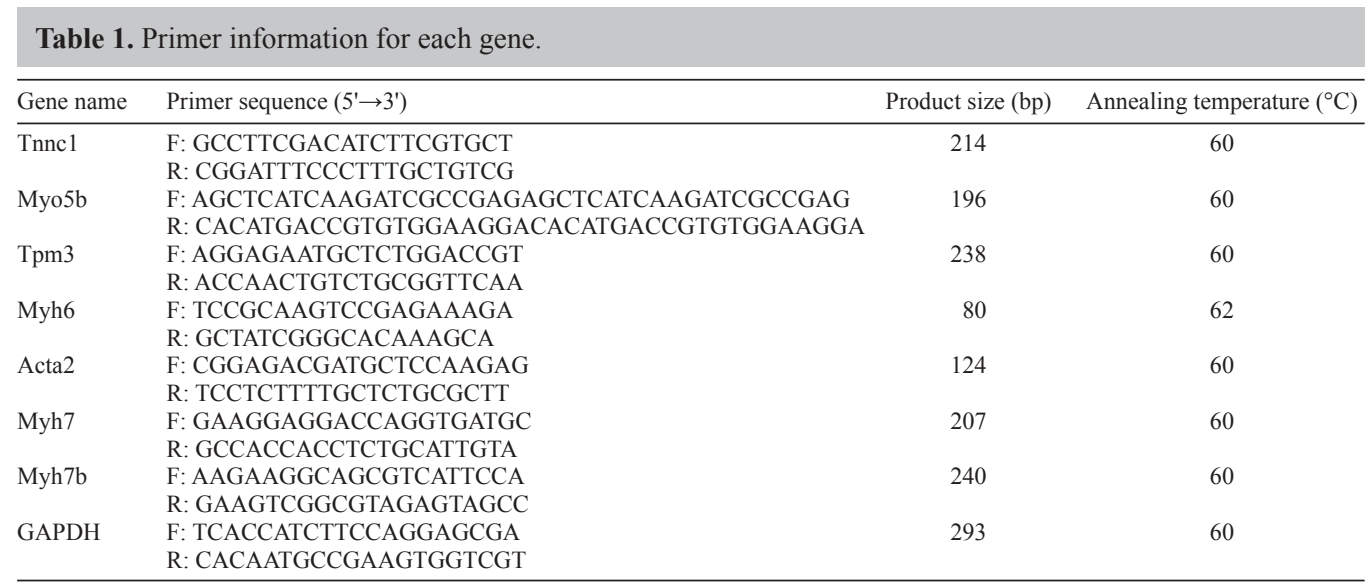

\section{cDNA preparation}

The reaction system was prepared using a SuperRT cDNA Kit (CoWin Biotech Corporation, Beijing, China) according to manufacturer instructions. The reaction system includ- 
ed $2 \mu \mathrm{L}$ RNA, $4 \mu \mathrm{L} 2.5 \mathrm{mM}$ dNTPs, $4 \mu \mathrm{L} 5 \mathrm{X}$ reverse transcription buffer, $1 \mu \mathrm{L} 200 \mathrm{U} / \mu \mathrm{L}$ SuperRT, and complement to $20 \mu \mathrm{L}$ with RNase-free water. The reaction conditions were as follows: $42^{\circ} \mathrm{C}$ for $40 \mathrm{~min} ; 80$ for $5 \mathrm{~min}$; and storage at $-20^{\circ} \mathrm{C}$ after completion of the reaction.

\section{Reverse transcription-polymerase chain reaction (RT-PCR)}

The RT-PCR Premix System was purchased from CoWin Biotech Corporation. The reaction system was optimized and prepared on ice according to manufacturer instructions, which included $2 \mathrm{X}$ UltraSYBR Mixture $(10 \mu \mathrm{L}$ with ROX), $0.4 \mu \mathrm{L}$ of each upstream and downstream, $2 \mu \mathrm{L}$ cDNA, and complement to $20 \mu \mathrm{L}$ with RNase-free water. The reaction conditions were as follows: $95^{\circ} \mathrm{C}$ for $10 \mathrm{~min} ; 40$ cycles at $95^{\circ} \mathrm{C}$ for $15 \mathrm{~s}$ and $60^{\circ} \mathrm{C}$ for $1 \mathrm{~min}$; $95^{\circ} \mathrm{C}$ for $15 \mathrm{~s}, 60^{\circ} \mathrm{C}$ for $1 \mathrm{~min}, 95^{\circ} \mathrm{C}$ for $15 \mathrm{~s}$, and $60^{\circ} \mathrm{C}$ for $15 \mathrm{~s}$. Each RT-PCR experiment was performed using 3 biological samples. For analysis, fluorescence signal values were obtained using an ABI 7500 Sequence Detection System Software (PE Applied Biosystems, Foster City, CA, USA), and the Ct value of each sample and gene was obtained. The $2^{-\Delta \Delta \mathrm{Ct}}$ method was used to calculate the differences in gene expression in multiples.

\section{RESULTS}

\section{Total RNA quality control results}

Total RNA was obtained by analog electrophoresis using an Agilent 2100 Bioanalyzer (Agilent Technologies) as shown in Figure 1, and the total RNA details are shown in Table 2.

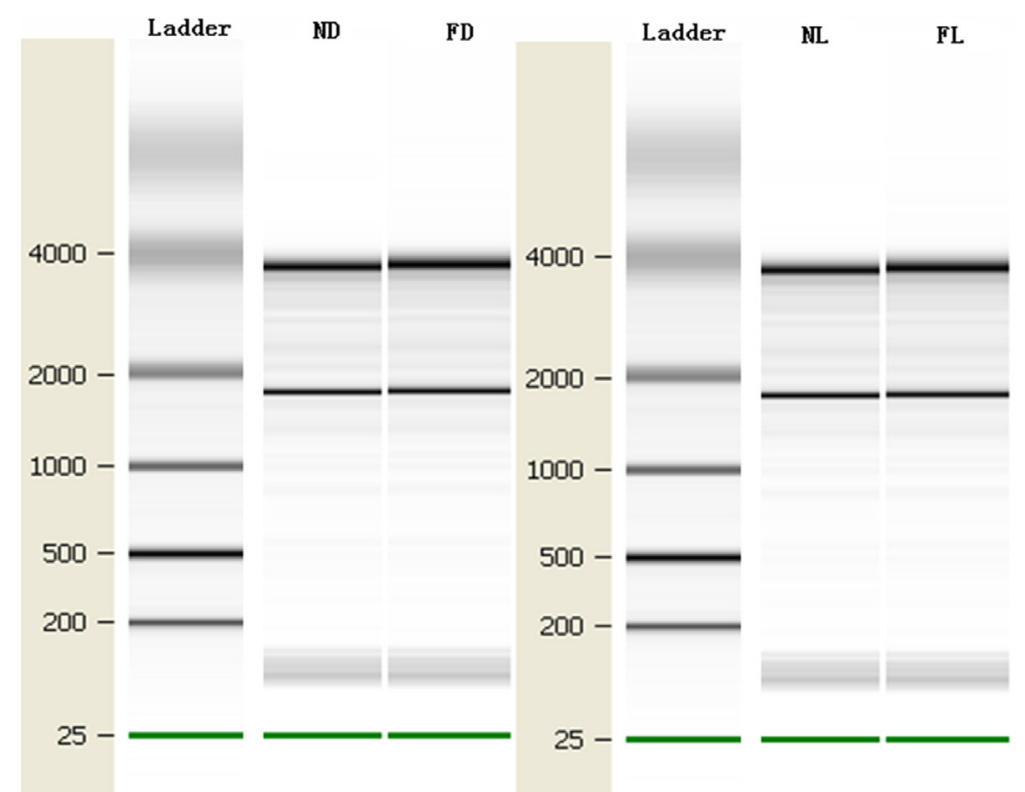

Figure 1. Total RNA analog electrophoresis (lane $N D=$ dorsal longissimus muscle of New Zealand white rabbits; lane $F D=$ dorsal longissimus muscle of Fujian yellow rabbits; lane $N L=$ leg muscle of New Zealand white rabbit; lane $F L=$ leg muscle of Fujian yellow rabbits). 


\begin{tabular}{|c|c|c|c|c|c|c|c|c|}
\hline \multirow[t]{2}{*}{ No. } & \multirow[t]{2}{*}{ Sample name } & \multirow[t]{2}{*}{ Concentration $(\mu \mathrm{g} / \mu \mathrm{L})$} & \multirow[t]{2}{*}{ Volume $(\mu \mathrm{L})$} & \multirow[t]{2}{*}{ Total $(\mu \mathrm{g})$} & \multirow{2}{*}{$\mathrm{OD}_{260 / 280}$} & \multicolumn{2}{|c|}{ Agilent 2100 result } & \multirow[t]{2}{*}{ Result } \\
\hline & & & & & & RIN & $28 \mathrm{~S} / 18 \mathrm{~S}$ & \\
\hline 1 & ND & 0.252 & 100 & 25.2 & 1.89 & 9.0 & 2.0 & Qualified \\
\hline 2 & NL & 0.470 & 100 & 47.0 & 1.91 & 8.7 & 2.1 & Qualified \\
\hline 3 & FD & 0.327 & 100 & 32.7 & 1.98 & 8.9 & 1.8 & Qualified \\
\hline 4 & FL & 0.387 & 100 & 38.7 & 1.98 & 8.7 & 1.9 & Qualified \\
\hline
\end{tabular}

Agilent 2100 RIN $\geq 7.0$ and $28 \mathrm{~S} / 18 \mathrm{~S} \geq 0.7$ indicates the sample is qualified, and further experiments can be conducted.

\section{Chip scan}

Scanning fluorescence signals were evaluated for each probe after completion of hybridization in the custom chips, reading data, and normalization processing.

\section{Selection of differentially expressed genes}

Normalized data were analyzed using the SAS online analysis system (SAS Institute, Inc., Cary, NC, USA), using the Fujian yellow rabbits as the experimental group and the New Zealand white rabbits as the control group. Differentially expressed genes that had changed in expression by more than 3-fold were screened in the dorsal longissimus and leg muscles of the 2 varieties. Fourteen genes associated with muscle development were screened in the dorsal longissimus muscle, including Myh6, Myh7, Myh7b, Myo5b, Tnnc1, Tpm3, Acta2, Myl6b, Ttn, Mtmr12, Myoc, Ablim1, My19, and Mylip. Thirteen genes associated with muscle development were screened in the leg muscle, including Myh6, Myh7, Myh7b, Myo5b, Tnnc1, Tpm3, Acta2, Myom3, MB, My12, My13, Tnnil1, and Atp2a2 (Guenet et al., 1996; Roof et al., 1997; Begley and Dixon, 2005; Schoenauer et al., 2008; Chen et al., 2010; Pegoraro et al., 2011; Polati et al., 2012; Hnia et al., 2012; Kararigas et al., 2012). Numerous differentially genes were identified (Figure 2).

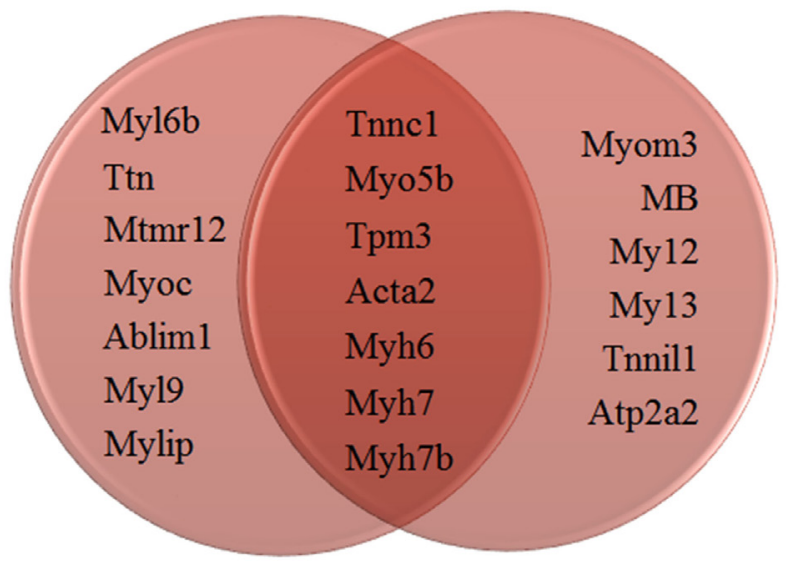

FD vs ND FL vs NL

Figure 2. Differentially expressed genes. In the left circle, 14 differentially expressed genes changed by more than 3 -fold and associated with muscle development were screened in the dorsal longissimus muscle. In the right circle, 13 genes were screened in the leg muscle. The shared part of the 2 circles shows 7 common differentially expressed genes. 


\section{Verification of the results}

The expression levels of the target genes in Fujian yellow rabbits relative to New Zealand white rabbits were consistent for each gene compared with the results of microarray analysis, with the exception of Acta2 (Figure 3). The results showed that the chip was reliable and that the differentially expressed genes should be further studied.

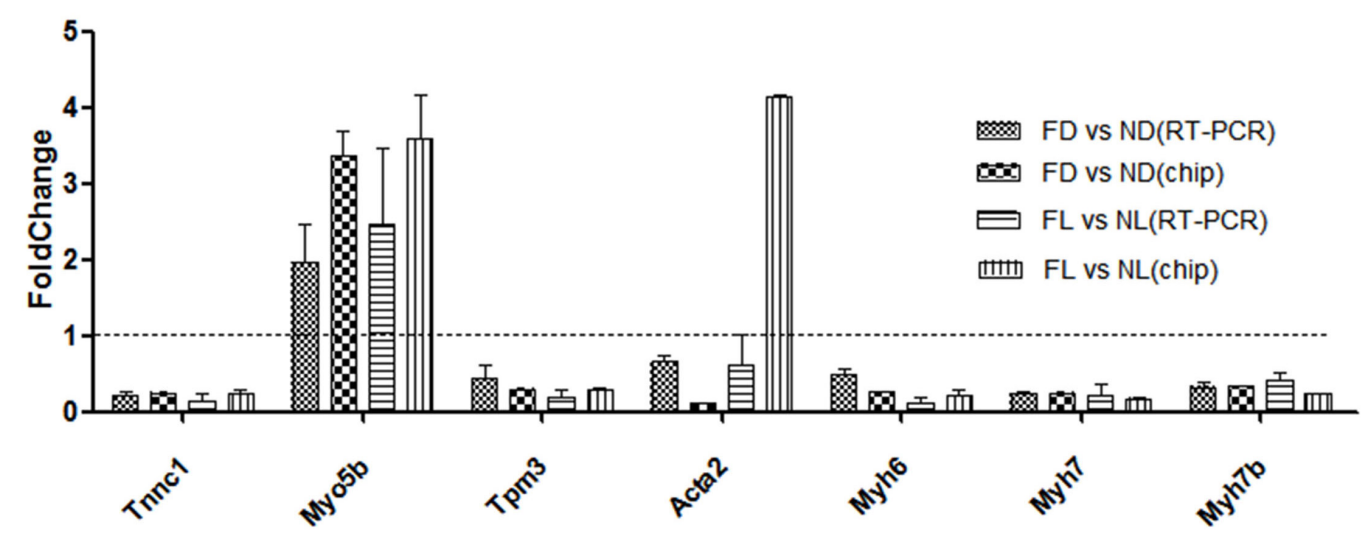

Figure 3. Comparison of the expression of each gene between RT-PCR and chip (fold-change value $>1$ indicated up-regulated and fold-change value $<1$ indicated down-regulated). In Fujian yellow rabbits and New Zealand white rabbits, the level of expression of all target genes were consistent in the dorsal longissimus muscle between RTPCR and chip. In leg muscle, most genes were consistent except for Acta2.

\section{DISCUSSION}

With the extensive application of molecular biology techniques in the field of agriculture, an increasing number of studies are using emerging techniques in basic research at the molecular level involving rabbit breeding. An expression profile chip is an important component of the gene chip; the manufacturing method is relatively well-studied, and microarray products from numerous different species can be used (Hughes et al., 2001). Using an expression profile chip, several studies have examined genetic changes in gene transcription and how gene expression levels are affected by drugs, diseases, or other interference. Yu et al. (2011) used genome microarray analysis and found that the differentially expressed genes between fetal ventricular septal defects in the myocardium and normal myocardium were related to signaling pathways in heart development. In recent years, the application of microarray technology has also extended to agriculture, such as for studying rice, flax, poplar, chickens, cattle, and geese (Cogburn et al., 2003; Arora et al., 2007; Zhao., 2010; Long et al., 2011; Zhu et al., 2011; Guifen et al., 2012). Real-time fluorescent quantitative PCR is necessary to ensure the reliability of the chip (Canales et al., 2006), and was used in the current study to test and verify some of the differences in gene expression.

In the current study, some differentially expressed genes between the Fujian yellow rabbits and New Zealand white rabbits with respect to the dorsal longissimus and leg muscles were selected in the Agilent rabbit, and then tested and verified by RT-PCR. The RT-PCR results showed that gene expression was consistent with the chip results. Thus, using the rabbit 
genome-wide chip to select differentially expressed genes in rabbit muscle is a reliable method of providing a reference for rabbit genetics and breeding.

The differentially expressed genes selected in the current study mainly included myosin, actin protein, troponin, and other critical components of muscle. For example, Myh6, Myh7, and Myh7b belong to the myosin heavy chain gene family (Suggs et al., 2007; van Rooij et al., 2009), and the role of myosin is to regulate muscle contraction for power. The Myh7 gene mutation rate is $41 \%$ in familial hypertrophic cardiomyopathy patients of Oriental descent (Song et al., 2005). Thus, the Myh7 gene plays an important role in regulating muscle development. The Tnnc1 gene belongs to the fast skeletal muscle troponin $\mathrm{C}$ gene family, which has $\mathrm{Ca}^{2+}$ binding and regulatory sites; the Tnncl gene is involved in intracellular $\mathrm{Ca}^{2+}$ signal transduction. A calciumregulated protein was discovered and found to regulate contraction of fast skeletal muscle (Farah and Reinach, 1995), thereby affecting the generation of muscle protein.

In the current study, a number of differentially expressed genes were selected in 2 varieties of meat rabbits using a gene expression profile chip (Myh6, Myh7, Myh7b, Myo5b, Tnnc1, Tpm3, and Acta2). The differentially expressed genes may be involved in rabbit muscle fiber formation and the muscle development process, and may be examined as target genes in studies of rabbit meat quality. The current study has provided a theoretical basis for improving rabbit meat quality and lays a foundation for future protection and exploitation of local meat rabbit varieties in China.

\section{ACKNOWLEDGMENTS}

Research supported by Modern Agricultural Industrial System Special Funding (\#CARS-44-1) and the Priority Academic Program Development of Jiangsu Higher Education Institutions (\#PAPD 2014-134).

\section{REFERENCES}

Arora R, Agarwal P, Ray S, Singh AK, et al. (2007). MADS-box gene family in rice: genome-wide identification, organization and expression profiling during reproductive development and stress. BMC Genomics 8: 242.

Begley MJ and Dixon JE (2005). The structure and regulation of myotubular in phosphatases. Curr. Opin. Struct. Biol. 15: 614-620.

Canales RD, Luo Y, Willey JC, Austermiller B, et al. (2006). Evaluation of DNA microarray results with quantitative gene expression platforms. Nat. Biotechnol. 24: 1115-1122.

Chen CP, Chiang MC, Wang TH, Hsueh C, et al. (2010). Microvillus inclusion disease: prenatal ultrasound findings, molecular diagnosis and genetic counseling of congenital diarrhea. Taiwan. J. Obstet. Gynecol. 49: 487-494.

Cogburn LA, Wang X, Carre W, Rejto L, et al. (2003). Systems-wide chicken DNA microarrays, gene expression profiling, and discovery of functional genes. Poult. Sci. 82: 939-951.

Farah C and Reinach F (1995). The troponin complex and regulation of muscle contraction. FASEB J. 9: 755-767.

Guenet JL, Simon-Chazottes D, Gravel M, Hastings KE, et al. (1996). Cardiac and skeletal muscle troponin I isoforms are encoded by a dispersed gene family on mouse chromosomes 1 and 7. Mamm. Genome 7: 13-15.

Guifen L, Xiaomu L, Fachun W, Xiuwen T, et al. (2012). Use a bovine genome chip to identify new biological pathways for beef quality in cattle. Mol. Biol. Rep. 39: 10979-10986.

Hnia K, Vaccari I, Bolino A and Laporte J (2012). Myotubular in phosphoinositide phosphatases: cellular functions and disease pathophysiology. Trends Mol. Med. 18: 317-327.

Hughes TR, Mao M, Jones AR, Burchard J, et al. (2001). Expression profiling using microarrays fabricated by an ink-jet oligonucleotide synthesizer. Nat. Biotechnol. 19: 342-347.

Kararigas G, Bito V, Tinel H, Becher E, et al. (2012). Transcriptome characterization of estrogen-treated human myocardium identifies myosin regulatory light chain interacting protein as a sex-specific element influencing contractile function. J. Am. Coll. Cardiol. 59: 410-417. 
Long SH, Chen XB and Qiu CS (2011). Use the cDNA Microarray to analysis on gene expression profile of flax in different environments. Plant Fiber Sci. China 32: 65-69.

Pegoraro C, Pollet N and Monsoro-Burq AH (2011). Tissue-specific expression of sarcoplasmic/endoplasmic reticulum calcium ATPases (ATP2A/SERCA) 1, 2, 3 during Xenopus laevis development. Gene Expr. Patterns 11: 122-128.

Polati R, Menini M, Robotti E, Millioni R, et al. (2012). Proteomic changes involved in tenderization of bovine longissimus dorsi muscle during prolonged ageing. Food Chem. 135: 2052-2069.

Roof DJ, Hayes A, Adamian M, Chishti AH, et al. (1997). Molecular characterization of abLIM, a novel actin-binding and double zinc finger protein. J. Cell Biol. 138: 575-588.

Schoenauer R, Lange S, Hirschy A, Ehler E, et al. (2008). Myomesin 3, a novel structural component of the M-band in striated muscle. J. Mol. Biol. 376: 338-351.

Song L, Zou Y, Wang J, Wang Z, et al. (2005). Mutations profile in Chinese patients with hypertrophic cardiomyopathy. Clin. Chim. Acta. 351: 209-216.

Suggs JA, Cammarato A, Kronert WA, Nikkhoy M, et al. (2007). Alternative S2 hinge regions of the myosin rod differentially affect muscle function, myofibril dimensions and myosin tail length. J. Mol. Biol. 367: 1312-1329.

van Rooij E, Quiat D, Johnson BA, Sutherland LB, et al. (2009). A family of microRNAs encoded by myosin genes governs myosin expression and muscle performance. Dev. Cell 17: 662-673.

Wu TW (2011). Rabbit hair follicle development regularity and genetic effects, expression characteristics of its associated gene. Doctoral thesis. Yangzhou University, Yangzhou.

Yu ZB, Han SP, Zhu C, Dong XY, et al. (2011). Screening and identification of genes in myocardial tissue of fetus with ventricular septal defect by using human genome microarray. J. Appl. Clin. Pediatr. 26: 1425-1428.

Zhao JX (2010). Study on the law of tree growth and development mined from genome expression microarray data of poplar. Anhui Agric. Sci. Bull. 16: 38-39.

Zhu LH, Meng H, Duan XJ, Xu GQ, et al. (2011). Gene expression profile in the liver tissue of geese after overfeeding. Poult. Sci. 90: 107-117. 